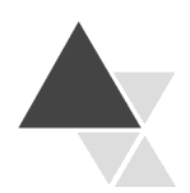

\title{
Programa Nacional de Alimentação Escolar: experiências da autogestão e da terceirizaçãa ${ }^{1}$
}

\author{
Mariana Schievano Danelon², Maria Angélica Schievano Danelon ${ }^{3}$, Marina Vieira da \\ Silva $^{4}$
}

Desde 1994 o Programa Nacional de Alimentação Escolar - PNAE vem sendo operacionalizado pelos estados e municípios (modelo de autogestão). Nos últimos anos, tendência crescente de adesão de municípios à terceirização do Programa tem sido observada em todas as regiões do Brasil. Esta pesquisa teve como objetivo avaliar os modelos de terceirização e de autogestão do PNAE e identificar as vantagens e desvantagens da sua adoção. A amostra envolveu duas unidades de ensino com jornada de período integral do município de Piracicaba (SP), sendo que em uma das escolas a Prefeitura era responsável pelo PNAE (autogestão) e na outra uma empresa prestadora de serviços de alimentação foi contratada, em caráter experimental. Foi realizado acompanhamento da rotina de execução do PNAE nas escolas, empregando-se roteiros especificamente elaborados para viabilizar a avaliação das condições de preparo e distribuição das refeições, da higiene nas etapas de produção, da adesão e da aceitabilidade dos alunos à alimentação e dos custos do Programa decorrentes dos modelos de gestão. Verificou-se que a aceitabilidade às refeições assemelhou-se à preconizada (85\%) pelo Ministério da Educação. Constatou-se que uma das principais dificuldades registradas pelos gestores públicos no que diz respeito à implementação do modelo de terceirização se refere à elaboração de documentos/editais onde constem especificações pormenorizadas dos contratos para prestação desse tipo de serviço. Como vantagem do sistema terceirizado, registra-se a disponibilidade de recursos para manutenção de infraestrutura e equipamentos do PNAE. O custo unitário da refeição distribuída no período do almoço alcançou R \$ 1,11 para a empresa terceirizada e R \$ 1,37 sob administração da Prefeitura. Não deve ser negligenciado o fato envolvendo o menor custo apresentado pela empresa, que pode ser atribuído à terceirização ter sido realizada em caráter experimental, sendo que a prestação de um serviço de qualidade por um custo reduzido, obviamente seria levada em consideração no processo de decisão da administração pública, no caso da opção, no futuro, recair sobre a gestão terceirizada (para o atendimento dos alunos da totalidade da rede de ensino).

Palavras-chave: alimentação escolar; autogestão; merenda escolar; terceirização.

\footnotetext{
${ }^{1}$ Artigo elaborado a partir da dissertação de Maria Angélica Schievano Danelon, intitulada "Programa de Alimentação Escolar em unidades de tempo integral: experiências e desafios de gestão". Universidade de São Paulo; 2007.

${ }^{2}$ Mestre em Ciências, Escola Superior de Agricultura "Luiz de Queiroz" (ESALQ), Universidade de São Paulo (USP). Endereço para correspondência: Rua MMDC, 167, Jaraguá, CEP: 13401-320, Piracicaba (SP). Brasil. E-mail: mariana.danelon@ig.com.br

${ }^{3}$ Mestre em Ciências, Escola Superior de Agricultura “Luiz de Queiroz” (ESALQ), Universidade de São Paulo (USP).

${ }^{4}$ Professora Doutora, Escola Superior de Agricultura “Luiz de Queiroz” (ESALQ). Universidade de São Paulo (USP).
} 


\section{Brazilian School Meal Program: experiences of self- management and outsourcing}

Since 1994, the Brazilian School Meal Program (PNAE) has been managed by states and city halls (selfmanagement). In the last few years, it has been observed, in all regions of the country, an increasing tendency of cities adhering to the Program's outsourcing. The present survey had as goal to evaluate the management models (outsourcing and self-management) of the PNAE and to identify pros and cons of their implementation. The sampling involved two units with full-time classes in Piracicaba (SP); in one of them, the city hall kept on managing the program (self-management) and, in the other, as an experience, the school meals were outsourced to a company specialized in food services. A PNAE routine assessment was performed in the units, applying routes specifically elaborated to try to obtain the information which could allow the evaluation of the meals' preparation and distribution, hygiene in the production phases, adhesion and acceptance of students to the meals distributed and the cost of the program due to different management models. It was verified that the meals' acceptance was similar to what was proclaimed (85\%) by the Education Ministry. One of the main difficulties registered by the public managers is concerned with the implementation of the outsourcing model, in terms of elaborating documents/summons where there are detailed specifications of the contracts for this kind of service. As advantages in the outsourced system, we identified the availability of resources for maintaining the infrastructure and equipment for the PNAE. The meal unit cost at lunchtime reached R\$1.11 for the outsourced company and $\mathrm{R} \$ 1.37$ for the city hall maintenance. We cannot neglect that the lower cost presented by the company can be attributed to the fact that the outsourcing was done as an experiment, and the provision of a quality service by a reduced cost would obviously be taken into account at the public administration's decision, in case it decides to adopt the (full) outsourced management for the program.

Key-words: school feeding; self-management; school meals; outsourcing

\section{Introdução}

O Programa Nacional de Alimentação Escolar - PNAE destaca-se por ser o mais antigo programa governamental de suplementação alimentar do país na área de educação, em vigor desde 1955. Ao longo deste período, o discurso que fundamenta o Programa foi sofrendo alterações, passando do combate à desnutrição e à evasão escolar, diretrizes iniciais, à garantia da alimentação escolar como um direito fundamental, assegurado pela Constituição, e inserida entre as políticas públicas prioritárias para a garantia da segurança alimentar e nutricional ${ }^{[1]}$.

Presente na totalidade das unidades públicas e filantrópicas de ensino infantil e fundamental, e a partir de 2009, atendendo também aos alunos matriculados no ensino médio, o PNAE tem como objetivo, por meio da distribuição de refeições que atendam as necessidades nutricionais dos alunos no período letivo, contribuir para o crescimento e o desenvolvimento biopsicossocial, a aprendizagem, o rendimento escolar e a formação de hábitos alimentares saudáveis ${ }^{[1]}$.

Desde a sua criação até meados da década de 90, o PNAE foi administrado de forma centralizada, na qual o órgão gerenciador planejava os cardápios, adquiria os gêneros por processo licitatório, contratava laboratórios especializados para efetuar $o$ controle de qualidade e responsabilizava-se pela distribuição dos alimentos em todo o território nacional ${ }^{[2]}$.

Com a descentralização administrativa do PNAE, ocorrida em 1994, por meio da Lei № 8.913, os recursos financeiros passaram, por meio da celebração de convênios, a ser 
enviados aos estados e municípios, delegandose a estes a competência para a operacionalização do Programa. Desde 1998, a transferência dos recursos, para a aquisição exclusiva de gêneros alimentícios, tem sido feita de forma direta, sem a necessidade de convênios, pelo Fundo Nacional de Desenvolvimento da Educação - FNDE às entidades executoras do Programa (estados e municípios, que podem também repassar os recursos diretamente às unidades de ensino integrantes das suas redes), sendo estas responsáveis pelo recebimento, complementação e administração dos recursos financeiros, elaboração dos cardápios, aquisição dos alimentos, preparo e distribuição da merenda, controle, avaliação e prestação de contas ao FNDE $^{[1,2]}$.

Com a descentralização, substanciais alterações foram sendo identificadas e continuam repercutindo sobre a operacionalização do programa, que podem refletir na melhoria de seu desempenho, tais como o planejamento das aquisições dos gêneros alimentícios viabilizado pela transferência de forma sistemática dos recursos financeiros; possibilidade de utilização de maior volume de produtos básicos in natura em substituição aos alimentos formulados; aquisição de alimentos da região, favorecendo a economia local e reduzindo custos de transporte dos gêneros; e implantação de produção alternativa de alimentos ${ }^{[2,3,4,5,6,7]}$.

No entanto, ainda persistem algumas dificuldades, enfrentadas pelas entidades executoras do Programa, especialmente no que se refere à escassez de recursos para atividades como manutenção da estrutura física das cozinhas e depósitos de gêneros, aquisição e conservação de equipamentos e utensílios e contratação de pessoal; além de processos licitatórios morosos, freqüentemente em descompasso com o calendário escolar e ainda, que priorizam o preço dos gêneros em detrimento da qualidade dos produtos ${ }^{[6,7,8]}$.

Uma alternativa considerada por alguns municípios (tais como as capitais São Paulo, Curitiba, Recife e São Luís, além de cidades de menor porte, como Sorocaba, Indaiatuba, Americana e Araçatuba, todas do interior paulista), para minimização dos problemas mencionados, tem sido a terceirização dos serviços de alimentação, transferindo para empresas prestadoras de serviços a responsabilidade pela execução do PNAE.

A terceirização dos serviços de alimentação escolar pode ser definida como um processo de gestão no qual, por meio do estabelecimento de contrato, delega-se a execução do Programa a empresas especializadas que se responsabilizam, conforme previamente estabelecido, pelo planejamento, aquisição e distribuição de gêneros alimentícios, contratação de recursos humanos, capacitação de pessoal, manutenção da estrutura física das cozinhas e dos equipamentos, sendo de responsabilidade do contratante, no caso, os municípios, o monitoramento e o controle das atividades realizadas pela empresa ${ }^{[9]}$.

Algumas vantagens são apontadas quanto à adoção do sistema de terceirização, como a otimização dos recursos; maior agilidade das decisões nos processos, especialmente referentes à aquisição de 
gêneros e à contratação de recursos humanos; e a possibilidade de dedicação dos técnicos do governo nas atividades de supervisão do programa ${ }^{[4]}$. Segundo Stolarski ${ }^{[8]}$, o custo do serviço terceirizado representa um fator limitante para o acesso e a adesão de expressiva parcela dos municípios a este modelo de gestão. Além dos custos, a dificuldade das entidades executoras quanto à elaboração de editais e contratos dos serviços também se constitui em entrave à adoção da terceirização ${ }^{[4]}$.

No município de Piracicaba (SP), três escolas, de um total de 52 unidades que integram rede de ensino fundamental, aderiram, no início de 2006, ao projeto do governo estadual "Escola de Tempo Integral", cujo objetivo refere-se à permanência do aluno na unidade de ensino por período integral (jornada de nove horas diárias). Em uma destas escolas, em caráter experimental, o preparo e a distribuição da alimentação escolar foram assumidos por uma empresa de serviços de alimentação (terceirização do serviço) e nas duas outras unidades de ensino o gerenciamento do PNAE continuou sob responsabilidade da Prefeitura Municipal (modelo de autogestão). Tal situação constituiu uma valiosa oportunidade de acompanhar e avaliar a adoção do processo de terceirização do PNAE.

Face ao exposto, este trabalho teve como objetivo avaliar a operacionalização de dois modelos de gestão (terceirização e autogestão) em escolas de período integral, identificando vantagens e desvantagens da sua adoção.

\section{Método}

A pesquisa, caracterizada como um estudo de caso, foi dsenvolvida no município de Piracicaba (SP), no período entre março e agosto de 2006. O projeto foi submetido ao Comitê de Ética em Pesquisa da Faculdade de Odontologia de Piracicaba, Universidade Estadual de Campinas, tendo sido aprovado sob o protocolo № $061 / 2006$.

A amostra envolveu a seleção de duas escolas do município de Piracicaba (SP), entre as três unidades que aderiram, em 2006, ao programa do governo estadual "Escola de Tempo Integral". No referido projeto, o PNAE deve fornecer aos alunos três refeições: lanches da manhã e tarde, nos quais são servidos biscoitos e produtos formulados (bebidas lácteas e preparações doces, como canjica e cremes) enviados pelo governo estadual, e refeição do almoço.

Na escola "A", definida por sorteio, a Prefeitura Municipal era responsável pela operacionalização do PNAE, envolvendo a distribuição dos alimentos enviados pelo governo estadual nos lanches da manhã e da tarde, e o preparo e a distribuição da refeição do almoço. Na unidade "B", uma empresa prestadora de serviços de alimentação foi contratada, em caráter experimental, para assumir a responsabilidade pelo preparo e distribuição da refeição do almoço durante o mês de março de 2006, devido à reforma da cozinha que até então sediava o PNAE naquela unidade. A refeição do almoço era preparada pelas merendeiras, contratadas da empresa, em unidade de ensino próxima à escola B e transportada até esta unidade integrante da pesquisa. $\mathrm{O}$ preparo e a 
distribuição dos alimentos fornecidos pelo estado de São Paulo para os lanches da manhã e da tarde, na unidade B, ficaram sob responsabilidade da Prefeitura. Reconhece-se, portanto, a limitação das análises envolvendo diferenças entre os modelos de gestão quando são avaliadas as refeições "lanches" (matutino e vespertino), pelo fato das mesmas, nas duas escolas, terem sido preparadas e distribuídas, por meio de serviços classificados na mesma modalidade (autogestão).

Realizou-se acompanhamento, por um período de cinco dias letivos em cada escola, da rotina de execução do PNAE. Incluiu-se, também, o monitoramento das atividades na cozinha da unidade na qual as refeições do almoço foram preparadas pela empresa prestadora de serviços e transportadas até a unidade B. Foram empregados roteiros especificamente elaborados para viabilizar a avaliação das condições de preparo e distribuição das refeições; da higiene nas etapas de produção; da adesão e da aceitabilidade dos alunos à alimentação; e dos custos do programa decorrentes dos modelos de gestão. Os manipuladores de alimentos (merendeiras), responsáveis pelo preparo das refeições nas unidades pesquisadas, foram entrevistados. As condições de estrutura física e a disponibilidade e conservação dos equipamentos das escolas foram avaliadas, identificando-se, também, as possíveis adaptações e reformas que a empresa terceirizada pudesse ter promovido na unidade onde foram produzidas as refeições.

O formulário para obtenção dos dados relativos à higiene foi adaptado do questionário elaborado por Silva ${ }^{[10]}$, tendo por base as Resoluções da Agência Nacional de
Vigilância Sanitária - ANVISA RDC 216, de

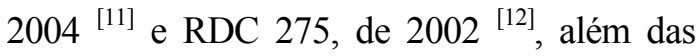
Portarias CVS 6/99, de $1999^{\text {[13] }}$, CVS № 30, de $1994^{[14]}$ e o Manual ABERC de práticas de elaboração e serviço de refeições para coletividades, de $2003^{[15]}$.

A avaliação das condições de preparo e distribuição das refeições envolveu o acompanhamento do modo de preparo, registrando-se os alimentos utilizados em gramas ou quilogramas (identificados por meio do uso de balança digital), o rendimento destes (avaliando-se a relação entre o peso dos alimentos preparados e crus) e o porcionamento (quantidade das preparações distribuída para os alunos, de forma individual). Foram utilizados os índices de conversão propostos por Araújo e Guerra ${ }^{[16]} \mathrm{e}$ Ornellas ${ }^{[17]}$, nos casos em que os alimentos nas etapas de pré-preparo não puderam ser pesados.

Para a avaliação da aceitação da alimentação escolar foi utilizada a metodologia de "Medidas de Sobras Agregadas", um dos métodos mais tradicionais para alcance deste objetivo. Foram adotados os procedimentos registrados por Moraes ${ }^{[18]}$ e Brandão ${ }^{[19]}$, que possibilitaram a verificação da quantidade de alimentos preparada, distribuída, as sobras limpas e os rejeitos. A determinação da quantidade elaborada das preparações foi realizada após o preparo e antecedendo a distribuição aos escolares, por meio da avaliação do peso ou volume dos alimentos, utilizando-se balança digital com capacidade máxima de 120 quilogramas e sensibilidade de 100 gramas. No momento da distribuição foi solicitado aos alunos que colocassem os rejeitos do prato em recipiente 
apropriado para posterior pesagem. As sobras limpas foram pesadas ao término de cada uma das refeições. O cálculo da aceitação das refeições baseou-se na fórmula:

$$
\% \text { de aceitação média }=\frac{\text { quantidade preparada }- \text { sobra limpa }- \text { rejeitos }}{\text { quantidade preparada }- \text { sobra limpa }} \times 100
$$

Foi adotado, para avaliação da percentagem de aceitação das refeições pelos escolares, o índice de aceitabilidade de no mínimo 85\%, estabelecido pelo Ministério da Educação ${ }^{[20]}$, por meio da Resolução № 32 , de 10 de agosto de 2006, para a avaliação das preparações do PNAE.

Uma desvantagem apontada por Brandão ${ }^{[19]}$ para o uso isolado da metodologia de "Medidas de Sobras Agregadas" é que não são considerados aqueles indivíduos que não apreciam a refeição a ponto de não consumila, ou que apreciam tanto que a repetem. Visando-se à minimização desta limitação metodológica, foram utilizados dois outros parâmetros: a percentagem de adesão ao programa e a percentagem de repetição.

A primeira consiste na proporção de escolares presentes diariamente na escola que de fato aderem ao PNAE. A adesão foi calculada com base na fórmula descrita a seguir:

$$
\% \text { de Adesão }=\frac{\text { № de escolares queaderiramao PNAE }}{\text { № de escolares presentes }}{ }^{*} \times 100
$$

Onde:

* $\mathrm{N}^{\mathrm{o}}$ de escolares presentes $=$ dados coletados junto às professoras em cada classe das unidades de ensino, visando-se à obtenção do número de alunos presentes diariamente na escola.

Devido à escassez de estudos que avaliem a adesão ao PNAE em escolas com jornada integral, empregou-se como critério de efetividade da participação dos alunos ao Programa, a classificação proposta por Sturion ${ }^{[6]}$, para as unidades com jornada tradicional de ensino: adesão alta (acima de $70 \%$ ), média (entre $50 \%$ e $70 \%$ ), baixa (entre $30 \%$ e $50 \%$ ) e muito baixa (inferior a $30 \%$ ).

A percentagem de repetição foi calculada a partir da fórmula:

$$
\% \text { de Repetição }=\frac{\text { № de escolares querepetemo cardápio }}{\text { № de escolares queaderiramao programa }} \times 100
$$


Destaca-se que nas duas unidades de ensino eram permitidas repetições das refeições.

Para a identificação dos custos dos diferentes modelos de gestão foi obtida planilha, junto à Secretaria da Educação da Prefeitura de Piracicaba (SP), contendo as especificações dos itens considerados para o cálculo, bem como os valores dos custos envolvidos no Programa, no ano de 2006. Na presente pesquisa, foram consideradas as despesas mensais (envolvendo dispêndios com recursos humanos; gêneros alimentícios e demais insumos; transporte de produtos; e despesas administrativas) por unidade de ensino, para a refeição do almoço.

Foram realizadas análises estatísticas descritivas, empregando-se o programa Statistical Analysis System - SAS, versão $8.2^{[21]}$.

\section{Resultados}

Além dos diferentes modelos de gestão adotados, as escolas que integraram a amostra apresentavam diferenças quanto às modalidades de ensino (Fundamental I e II) atendidas, à faixa etária dos alunos matriculados e à localização (Tabela 1).

Tabela 1 - Características selecionadas das unidades de ensino que integraram a pesquisa.

Piracicaba, 2006

\begin{tabular}{lrr}
\hline Características & \multicolumn{1}{c}{ Escola A } & \multicolumn{1}{c}{ Escola B } \\
\hline $\mathrm{N}^{0}$ de alunos matriculados & 390 & 493 \\
$\mathrm{~N}^{\mathrm{o}}$ de classes & 11 & 13 \\
Séries mantidas pelas & Ensino Fundamental II & Ensino Fundamental I e II \\
unidades & $\left(5^{\mathrm{a}}\right.$ a $8^{\mathrm{a}}$ séries $)$ & $\left(1^{\mathrm{a}}\right.$ a $8^{\mathrm{a}}$ séries $)$ \\
Faixa etária dos alunos & 10 a 14 anos & 7 a 14 anos \\
Localização & Central & Periférica \\
Modalidade de gestão do & Autogestão (Prefeitura & Serviço terceirizado no \\
PNAE & Municipal) & primeiro semestre de 2006 \\
\hline
\end{tabular}

As proporções médias de aceitação dos alunos às refeições distribuídas pelo PNAE aproximaram-se ou superaram o índice preconizado $(85 \%)$ pelo Ministério da Educação ${ }^{[20]}$, nas duas unidades de ensino (Tabela 2). 
Tabela 2 - Aceitação das refeições do Programa Nacional de Alimentação Escolar pelos alunos, de acordo com a unidade de ensino. Piracicaba, 2006

\begin{tabular}{|c|c|c|c|c|c|c|}
\hline \multirow[b]{2}{*}{ Escolas } & \multicolumn{6}{|c|}{ Percentagem de Aceitação das Refeições } \\
\hline & $\begin{array}{l}\text { Segunda } \\
\text {-feira }\end{array}$ & $\begin{array}{l}\text { Terça- } \\
\text { feira }\end{array}$ & $\begin{array}{l}\text { Quarta- } \\
\text { feira }\end{array}$ & $\begin{array}{l}\text { Quinta- } \\
\text { feira }\end{array}$ & $\begin{array}{l}\text { Sexta- } \\
\text { feira }\end{array}$ & $\begin{array}{c}\text { Média } \\
( \pm \text { Desvio Padrão })\end{array}$ \\
\hline \multicolumn{7}{|l|}{ A (autogestão) } \\
\hline Lanche da manhã & 73 & 91 & 93 & 96 & 82 & $87 \pm 8$ \\
\hline Almoço & 76 & 88 & 80 & 81 & 84 & $82 \pm 4$ \\
\hline Lanche da tarde & 96 & 96 & 96 & 89 & 95 & $95 \pm 3$ \\
\hline \multicolumn{7}{|l|}{ B (terceirizada)* } \\
\hline Lanche da manhã & 90 & 88 & 93 & 89 & 93 & $91 \pm 2$ \\
\hline Almoço & 85 & 88 & 90 & 85 & 89 & $87 \pm 2$ \\
\hline Lanche da tarde & 97 & 95 & 97 & 96 & 98 & $97 \pm 1$ \\
\hline \multicolumn{7}{|c|}{$\begin{array}{l}\text { *Na unidade B apenas a refeição do almoço foi terceirizada, sendo que os lanches (manhã e tarde) ficaram sob } \\
\text { responsabilidade da Prefeitura Municipal (autogestão). }\end{array}$} \\
\hline \begin{tabular}{l}
\multicolumn{2}{c}{ No que se } \\
ao Programa (T \\
valores medianos
\end{tabular} & $\begin{array}{l}\text { fere à ades } \\
\text { ela } 3 \text { ), } \\
\text { adesão }\end{array}$ & $\begin{array}{l}\text { o dos al } \\
\text { erificarat } \\
\text { aliment }\end{array}$ & & \multicolumn{3}{|c|}{$\begin{array}{l}\text { distribuída nos lanches da manhã e da tarde, } \\
\text { em ambas as escolas. Maiores percentuais de } \\
\text { adesão foram identificados para as refeições } \\
\text { distribuídas no período do almoço. }\end{array}$} \\
\hline
\end{tabular}

Tabela 3 - Adesão dos alunos às refeições distribuídas pelo Programa Nacional de Alimentação Escolar, de acordo com a unidade de ensino. Piracicaba, 2006

\begin{tabular}{lcccccc}
\hline \multirow{2}{*}{ Escolas } & \multicolumn{5}{c}{ Percentagem de Adesão dos Escolares às Refeições } \\
\cline { 2 - 7 } & $\begin{array}{c}\text { Segunda } \\
\text {-feira }\end{array}$ & $\begin{array}{c}\text { Terça- } \\
\text { feira }\end{array}$ & $\begin{array}{c}\text { Quarta- } \\
\text { feira }\end{array}$ & $\begin{array}{c}\text { Quinta- } \\
\text { feira }\end{array}$ & $\begin{array}{c}\text { Sexta- } \\
\text { feira }\end{array}$ & $\begin{array}{c}\text { Média } \\
\text { (土 Desvio Padrão) }\end{array}$ \\
\hline A (autogestão) & & & & & & \\
Lanche da manhã & 72 & 61 & 69 & 58 & 72 & $66 \pm 6$ \\
Almoço & 80 & 82 & 83 & 81 & 71 & $79 \pm 4$ \\
Lanche da tarde & 63 & 65 & 70 & 47 & 60 & $61 \pm 8$ \\
B (terceirizada)* & & & & & & \\
Lanche da manhã & 51 & 63 & 57 & 59 & 49 & $56 \pm 5$ \\
Almoço & 87 & 96 & 88 & 99 & 80 & $90 \pm 7$ \\
Lanche da tarde & 64 & 66 & 65 & 80 & 64 & $68 \pm 6$ \\
\hline
\end{tabular}

*Na unidade B apenas a refeição do almoço foi terceirizada, sendo que os lanches (manhã e tarde) ficaram sob responsabilidade da Prefeitura Municipal (autogestão).

Quando se analisa a percentagem de repetições (Tabela 4), a proporção de alunos da unidade A que repetiu a refeição do almoço (4\%) se mostrou muito inferior à observada na escola B (44\%). No entanto, esclarece-se que na unidade A (autogestão), durante os cinco dias de acompanhamento da rotina do Programa, as quantidades preparadas dos alimentos não foram suficientes para que parcela de alunos pudesse repetir a refeição. Outro aspecto a ser considerado refere-se ao fato de que na unidade B (gestão terceirizada) o volume médio das porções (valor per capita), para a refeição do almoço, foi inferior $(196 \mathrm{~g} \pm 18 \mathrm{~g})$ ao distribuído na unidade A $(256 \mathrm{~g} \pm 50 \mathrm{~g})$. Nas refeições dos lanches (da manhã e da tarde) também foram identificadas maiores porções (valor médio de $168 \mathrm{~g} \pm 29 \mathrm{~g}$ ) servidas para os alunos da unidade A em 
comparação ao atendimento dos alunos da escola B $(122 \mathrm{~g} \quad \pm 2 \mathrm{~g})$. $\mathrm{O}$ reduzido porcionamento das preparações representa aspecto que pode ter contribuído para a expressiva percentagem de repetições na unidade terceirizada (Tabela

$4)$.

Tabela 4 - Repetições das refeições do Programa Nacional de Alimentação Escolar, pelos alunos, de acordo com a unidade de ensino. Piracicaba, 2006

\begin{tabular}{|c|c|c|c|c|c|c|}
\hline \multirow[b]{2}{*}{ Escolas } & \multicolumn{6}{|c|}{ Percentagem de Repetição dos Escolares às Refeições } \\
\hline & $\begin{array}{l}\text { Segunda } \\
\text {-feira }\end{array}$ & $\begin{array}{l}\text { Terça- } \\
\text { feira }\end{array}$ & $\begin{array}{l}\text { Quarta- } \\
\text { feira }\end{array}$ & $\begin{array}{l}\text { Quinta- } \\
\text { feira }\end{array}$ & $\begin{array}{c}\text { Sexta- } \\
\text { feira }\end{array}$ & $\begin{array}{c}\text { Média } \\
( \pm \text { Desvio Padrão) }\end{array}$ \\
\hline \multicolumn{7}{|l|}{ A (autogestão) } \\
\hline Lanche da manhã & 15 & 13 & 10 & 22 & 06 & $13 \pm 5$ \\
\hline Almoço & 06 & 03 & 03 & 04 & 04 & $4 \pm 1$ \\
\hline Lanche da tarde & 20 & 17 & 35 & 36 & 10 & $24 \pm 10$ \\
\hline \multicolumn{7}{|l|}{ B (terceirizada)* } \\
\hline da manhã & 14 & 23 & 32 & 14 & 16 & $20 \pm 7$ \\
\hline $\mathrm{Al}$ & 33 & 48 & 44 & 50 & 47 & $44 \pm 6$ \\
\hline Lanche da tarde & 22 & 05 & 17 & 45 & 22 & $22 \pm 13$ \\
\hline \multicolumn{7}{|c|}{$\begin{array}{l}\text { *Na unidade B apenas a refeição do almoço foi terceirizada, sendo que os lanches (manhã e tarde) ficaram sob } \\
\text { responsabilidade da Prefeitura Municipal (autogestão). }\end{array}$} \\
\hline \multicolumn{4}{|c|}{$\begin{array}{l}\text { Julgou-se pertinente avaliar a } \\
\text { disponibilidade de recursos (humanos, } \\
\text { estrutura física e condições de higiene no } \\
\text { preparo e nas instalações do Programa) nos } \\
\text { dois modelos de gestão do PNAE. }\end{array}$} & \multicolumn{3}{|c|}{$\begin{array}{l}\text { meio de empresa terceirizada. Na escola B } \\
\text { (terceirizada), entrevistaram-se os } \\
\text { manipuladores da empresa terceirizada } \\
\text { responsável pela refeição do almoço, e uma } \\
\text { merendeira funcionária da Prefeitura, que era } \\
\text { encarregada da distribuição das refeições nos } \\
\text { períodos dos lanches (matutino e vespertino). }\end{array}$} \\
\hline $\begin{array}{l}\text { No que } \\
\text { humanos, realizou } \\
\text { equipe de três m } \\
\text { (autogestão), contr }\end{array}$ & $\begin{array}{l}\text { e refere } \\
\text { se entrevis } \\
\text { rendeiras } r \\
\text { tada pela }\end{array}$ & $\begin{array}{l}\text { os recu } \\
\text { com } \\
\text { unidade } \\
\text { refeitura }\end{array}$ & & $\begin{array}{l}\text { períodos dos } \\
\text { A caracteriz } \\
\text { com indicad } \\
\text { Tabela } 5 .\end{array}$ & $\begin{array}{l}\text { anches }( \\
\text { ão das } 1 \\
\text { es selec }\end{array}$ & $\begin{array}{l}\text { atutino e vespertino). } \\
\text { erendeiras, de acordo } \\
\text { nados, é disposta na }\end{array}$ \\
\hline
\end{tabular}


Tabela 5 - Perfil das merendeiras que trabalhavam nas unidades de ensino integrantes da pesquisa, de acordo com indicadores selecionados. Piracicaba, 2006

\begin{tabular}{|c|c|c|c|}
\hline \multirow[b]{3}{*}{ Indicadores avaliados } & \multicolumn{3}{|c|}{ Escolas } \\
\hline & \multirow{2}{*}{$\begin{array}{c}\text { A (autogestão) } \\
\text { Merendeiras } \\
\text { contratadas pela } \\
\text { Prefeitura por meio de } \\
\text { empresa terceirizada }\end{array}$} & \multicolumn{2}{|c|}{ B (terceirizada) } \\
\hline & & $\begin{array}{c}\text { Merendeiras } \\
\text { contratadas pela } \\
\text { empresa } \\
\text { terceirizada } \\
\text { responsável pela } \\
\text { refeição do almoço }\end{array}$ & $\begin{array}{c}\text { Merendeira } \\
\text { contratada pela } \\
\text { Prefeitura } \\
\text { (funcionária pública } \\
\text { municipal) }\end{array}$ \\
\hline Escolaridade & $\begin{array}{l}66,7 \% \text { fundamental } \\
\text { completo e } 33,3 \% \\
\text { médio completo }\end{array}$ & $\begin{array}{c}66,7 \% \text { fundamental } \\
\text { completo e } 33,3 \% \\
\text { superior incompleto }\end{array}$ & superior incompleto \\
\hline Salário mensal (R\$)* & 460,00 & 430,00 & 650,00 \\
\hline Carga horária semanal & 44 & 44 & 40 \\
\hline Tempo de contratação & Inferior há 1 ano & $\begin{array}{c}\text { Desde a recém } \\
\text { contratação até } 3 \\
\text { anos }\end{array}$ & 10 anos \\
\hline $\begin{array}{l}\text { Frequência de realização } \\
\text { de exames laboratoriais } \\
\text { (fezes, urina e sangue) }\end{array}$ & $\begin{array}{l}\text { Admissão e } 1 \text { vez por } \\
\text { ano }\end{array}$ & $\begin{array}{l}\text { Admissão e } 1 \text { vez } \\
\text { por ano }\end{array}$ & $\begin{array}{l}\text { Admissão, sendo os } \\
\text { exames refeitos } \\
\text { esporadicamente } \\
\text { (frequência menor } \\
\text { que } 1 \text { vez por ano) } \\
\end{array}$ \\
\hline $\begin{array}{l}\text { Participação em cursos } \\
\text { de treinamento }\end{array}$ & $\begin{array}{l}\text { Admissão e curso de } \\
\text { reciclagem semestral }\end{array}$ & $\begin{array}{l}\text { Admissão e curso } \\
\text { de reciclagem anual }\end{array}$ & $\begin{array}{l}\text { Admissão e curso } \\
\text { de reciclagem anual }\end{array}$ \\
\hline $\begin{array}{l}\text { Atribuições } \\
\text { desenvolvidas nas } \\
\text { escolas }\end{array}$ & $\begin{array}{l}\text { Em ambas as unidades } \\
\text { de estoque, o recebime } \\
\text { o preparo, a distribui } \\
\text { higienização das insta } \\
\text { estoque) }\end{array}$ & $\begin{array}{l}\text { S merendeiras afirma } \\
\text { to e a estocagem de } q \\
\text { ão, o registro das } r \\
\text { ções do serviço de a }\end{array}$ & $\begin{array}{l}\text { m realizar o controle } \\
\text { neros, o pré-preparo, } \\
\text { eições servidas e a } \\
\text { mentação (cozinha e }\end{array}$ \\
\hline
\end{tabular}

*Valores do salário mínimo à época da pesquisa: R\$ 300,00 (mês de março de 2006) e R\$ 350,00 (agosto de 2006).

Avaliando-se a estrutura física disponível nas unidades de ensino (escola A, administrada pela Prefeitura, e escola próxima à $\mathrm{B}$, na qual foram preparadas as refeições pela empresa, para posterior transporte à unidade B), verificou-se que estas apresentavam problemas especialmente nas instalações hidráulicas. As unidades não atendiam requisitos necessários para a conservação dos alimentos, tais como a presença de telas nas portas e janelas e de proteção nos ralos. Os sanitários utilizados pelas merendeiras não eram exclusivos e nas cozinhas não havia lavatórios específicos para a higienização das mãos. Os locais para pré-preparo não eram isolados da área de preparo por barreira física ou técnica, dificultando o fluxo de produção. $\mathrm{Na}$ unidade A também foram observadas ausências de iluminação, ventilação e de produtos para a adequada higiene pessoal.

Destaca-se que a empresa terceirizada não realizou expressivas alterações na estrutura física no local de preparo das refeições, tendo em vista a limitação do contrato com a Prefeitura (cerca de um mês). As principais alterações promovidas pela empresa referiram-se à realização de reparos 
no sistema hidráulico e a consertos e aquisição de equipamentos e utensílios.

Na Tabela 6 são apresentadas as principais características avaliadas quanto às

Tabela 6 - Condições higiênicas nas unidades de ensino integrantes da pesquisa. Piracicaba, 2006

\begin{tabular}{|c|c|c|}
\hline Características de higiene avaliadas & $\begin{array}{c}\text { Escola A } \\
\text { (autogestão) }\end{array}$ & $\begin{array}{c}\text { Escola B } \\
\text { (terceirizada) }\end{array}$ \\
\hline Frequência correta de higienização das instalações & Sim & Não \\
\hline $\begin{array}{l}\text { Produtos de higienização regularizados pelo Ministério da Saúde } \\
\text { e utilizados adequadamente (diluição, tempo de contato, modo } \\
\text { de uso) }\end{array}$ & Não & Sim \\
\hline $\begin{array}{l}\text { Utensílios e equipamentos higienizados adequadamente e } \\
\text { protegidos da contaminação }\end{array}$ & Não & Sim \\
\hline Lixo acondicionado e higienizado adequadamente & Sim & Sim \\
\hline $\begin{array}{l}\text { Uso de uniforme completo e limpo pelos manipuladores, } \\
\text { adequado asseio pessoal (ausência de adornos) }\end{array}$ & Sim & Sim \\
\hline Presença de produtos adequados para higienização das mãos & Não & Sim \\
\hline $\begin{array}{l}\text { Práticas sanitárias adequadas na manipulação dos alimentos (não } \\
\text { espirrar, tossir, falar, manipular dinheiro, entre outros) }\end{array}$ & Sim & Sim \\
\hline Medição de temperatura no recebimento de perecíveis & Não & Não \\
\hline Inexistência de produtos com validade vencida & Não & Sim \\
\hline Armazenamento adequado de matérias primas e ingredientes & Sim & Sim \\
\hline $\begin{array}{l}\text { Rede de frio adequada para armazenamento de matérias primas e } \\
\text { produtos manipulados }\end{array}$ & Sim & Sim \\
\hline $\begin{array}{l}\text { No pré-preparo, correta desinfecção em solução clorada de } \\
\text { hortaliças e frutas }\end{array}$ & Não & Sim \\
\hline Descongelamento adequado & Não & Sim \\
\hline $\begin{array}{l}\text { Os alimentos quentes eram mantidos em temperatura adequada } \\
\left(\geq 65^{\circ} \mathrm{C}\right) \text { até o momento da distribuição }\end{array}$ & Sim & Sim \\
\hline $\begin{array}{l}\text { As preparações permaneciam em temperatura adequada até o } \\
\text { final da distribuição }\end{array}$ & Não & Sim \\
\hline A temperatura dos alimentos é monitorada durante a distribuição & Não & Não \\
\hline $\begin{array}{l}\text { Há programação das quantidades preparadas, evitando a } \\
\text { ocorrência de sobras das preparações }\end{array}$ & Sim & Sim \\
\hline Existência de programa de amostragem para análise laboratorial & Não & Sim \\
\hline Transporte das refeições prontas em temperatura adequada & $\begin{array}{l}\text { Não se } \\
\text { aplica }\end{array}$ & Sim \\
\hline $\begin{array}{l}\text { Existência de manual de Boas Práticas de Fabricação e dos } \\
\text { Procedimentos Operacionais Padronizados - POP }\end{array}$ & Não & Sim \\
\hline
\end{tabular}

Tendo em vista a importância de se dispor de dados e análises envolvendo custos, foram calculados os dispêndios mensais do condições higiênicas na operacionalização do PNAE. 
Tabela 7 - Composição dos custos do Programa Nacional de Alimentação Escolar - PNAE, de acordo com o modelo de gestão. Piracicaba, 2006

\begin{tabular}{|c|c|c|c|c|}
\hline \multirow[b]{2}{*}{ Itens } & \multicolumn{2}{|c|}{$\begin{array}{c}\text { PNAE (para escolas com } \\
\text { jornada tradicional de aulas) }\end{array}$} & \multicolumn{2}{|c|}{$\begin{array}{l}\text { PNAE (para escolas } \\
\text { com período integral) }\end{array}$} \\
\hline & Quantidade & $\begin{array}{l}\text { Custo mensal } \\
\text { do Programa } \\
\text { (em Reais) }\end{array}$ & $\begin{array}{l}\text { Escola A - } \\
\text { autogestão } \\
\text { (em Reais) }\end{array}$ & $\begin{array}{l}\text { Escola B - } \\
\text { terceirizada } \\
\text { (em Reais) }\end{array}$ \\
\hline 1. Mão de obra (salários, encargos e & 167 & $147.052,10$ & $3.468,13$ & $1.757,79^{(1)}$ \\
\hline \multicolumn{5}{|l|}{ 1.1 Merendeira (contratada pela } \\
\hline $\begin{array}{l}\text { Prefeitura) } \\
\quad 1.2 \text { Merendeira (contratada pela }\end{array}$ & 40 & $42.501,10$ & 0,00 & $1.062,53$ \\
\hline Prefeitura de empresa terceirizada) & 74 & $68.397,44$ & $2.772,87$ & 0,00 \\
\hline 1.3 Administrativo & 53 & $36.153,56$ & 695,26 & 695,26 \\
\hline \multicolumn{5}{|l|}{ 2. Programa de Integração Social - } \\
\hline \multicolumn{5}{|l|}{ PIS e Programa de Formação do } \\
\hline \multicolumn{5}{|l|}{ Patrimônio do Servidor Público - } \\
\hline \multicolumn{5}{|l|}{ PASEP (merendeiras e pessoal de } \\
\hline 3. Insumos/Equipamentos & - & $128.068,59$ & $3.020,55$ & $62,85^{(2)}$ \\
\hline 3.1 Gêneros alimentícios e gás & - & $124.849,90$ & $2.961,82$ & 0,00 \\
\hline 3.2 Uniforme & - & 164,69 & 0,00 & 4,12 \\
\hline \multicolumn{5}{|l|}{ 3.3 Materiais/Serviços de apoio } \\
\hline administrativo & - & $3.054,00$ & 58,73 & 58,73 \\
\hline \multicolumn{5}{|l|}{ 4. Fornecimento de energia elétrica } \\
\hline \multicolumn{5}{|l|}{ 5. Serviços de telecomunicações (setor } \\
\hline administrativo) & - & 413,21 & 8,10 & $-{ }^{(3)}$ \\
\hline \multicolumn{5}{|l|}{ 6. Frota de veículos (combustível e } \\
\hline \multicolumn{5}{|l|}{$\begin{array}{l}\text { (gêneros alimentícios, gás, transporte, } \\
\text { mão-de-obra, gastos do setor } \\
\text { administrativo, entre outros, sob } \\
\text { responsabilidade da empresa }\end{array}$} \\
\hline prestadora do serviço) & - & - & 0,00 & $4.800,00$ \\
\hline Total dos custos & & $281.814,31$ & $6.619,02$ & $6.668,54$ \\
\hline № de refeições servidas & & 418.765 & 4.845 & 6.000 \\
\hline Valor por refeições & & 0,67 & 1,37 & 1,11 \\
\hline $\begin{array}{l}\text { (1) Valor referente ao custo (Prefeitura Munici } \\
\text { (matutino e vespertino), na escola B. Os custos } \\
\text { preparo e distribuição da refeição do almoço, es } \\
\text { (2) Valor referente ao custo (Prefeitura Munici } \\
\text { lanches (matutino e vespertino), na escola B. } \\
\text { incluídos no item } 7 \text { da Tabela. }\end{array}$ & $\begin{array}{l}\text { oal) com a mão } \\
\text { relativos à mão } \\
\text { ão incluídos no i } \\
\text { pal) com insumo } \\
\text { Os custos da em }\end{array}$ & $\begin{array}{l}\text { e obra necessária } \\
\text { le obra empregada } \\
\text { m } 7 \text { da Tabela. } \\
\text { equipamentos nece } \\
\text { esa terceirizada co }\end{array}$ & $\begin{array}{l}\text { a a distribuiç } \\
\text { la empresa te } \\
\text { ários para a c }\end{array}$ & $\begin{array}{l}\text { ão dos lanches } \\
\text { ceirizada, para } \\
\text { istribuição dos } \\
\text { pamentos estão }\end{array}$ \\
\hline
\end{tabular}




\section{Discussão}

Nas duas unidades de ensino pesquisadas as proporções médias de aceitação (Tabela 2) aproximaram-se ou superaram o índice preconizado (85\%) pelo Ministério da Educação [20], resultado que pode ser considerado satisfatório, e que encontra concordância com estudo transversal, conduzido por Martins et al. ${ }^{[22]}$ em 2002, realizado em 12 escolas, operacionalizadas em autogestão, no município de Piracicaba (SP). No referido estudo foi identificado índice de aceitação que variou entre $73 \%$ e $97 \%$, valores que segundo os autores sugerem boa aceitação das preparações entre os alunos.

O menor valor médio de aceitação (82\%) foi observado para as refeições do almoço distribuídas pela unidade A (autogestão). O cardápio servido nesta escola, no período do almoço, que obteve a menor aceitação foi o composto por arroz, feijão, omelete com legumes e salada de alface com tomate. Martins et al. ${ }^{[22]}$ e Flávio ${ }^{[23]}$ estudando as preferências dos escolares quanto aos cardápios do PNAE verificaram que aqueles que continham preparações envolvendo ovos (tais como salada de legumes com ovos; ou arroz, feijão e ovos mexidos) foram citados pelos alunos entre os menos apreciados.

Quanto ao cardápio distribuído na quarta-feira, na unidade A, uma das principais motivações para rejeição das refeições foi o fato das merendeiras da escola terem preparado "arroz com vagem", sendo que expressiva parcela dos alunos que aderiu à alimentação recusou a preparação, devido à presença da leguminosa.
$\mathrm{Na}$ quinta-feira, foram utilizados produtos formulados para o preparo da refeição na escola A, como "frango em molho" e "purê de batatas", enviados pelo Departamento de Suprimento ao Escolar DSE, do estado de São Paulo, às escolas com jornada integral. O uso de tais produtos pode ter interferido negativamente na aceitabilidade das refeições.

Segundo Nogueira ${ }^{[4]}$ e Vianna e
Tereso [24], os alimentos formulados
apresentam reduzida aceitabilidade entre os
escolares, constituindo-se em produtos
monótonos e inadequados quanto aos hábitos
alimentares dos beneficiários do Programa. Cabe destacar, no entanto, que estes produtos foram utilizados no cardápio do almoço em um único dia da semana. Nota-se, que nos casos das bebidas lácteas, também enviadas pelo DSE de São Paulo, a aceitação pode ser considerada satisfatória. Como vantagens desses alimentos apontam-se o aspecto operacional ${ }^{[24]}$, a regularidade da oferta, a baixa perecibilidade, a facilidade no transporte e no armazenamento e a simplicidade no preparo $^{[4,5]}$.

Analisando-se a adesão dos alunos à alimentação distribuída nos lanches da manhã e da tarde (Tabela 3), destaca-se que as diferenças observadas entre as unidades de ensino podem, em parte, serem explicadas pelos distintos grupamentos etários atendidos pelas escolas (Tabela 1). Na unidade A, frequentada apenas por alunos de maior idade (entre 10 e 14 anos pertencentes ao ensino fundamental II), maior proporção aderiu ao lanche da manhã, no qual era distribuída bebida láctea quente. A menor adesão no período da tarde nesta unidade foi na quinta- 
feira, para a preparação doce "canjica". Na unidade $\mathrm{B}$, que possui alunos matriculados com idade entre 7 e 14 anos (ensino fundamental I e II), maior proporção de escolares aderiu ao lanche da tarde, no qual eram servidas bebidas lácteas mais adocicadas, à temperatura ambiente. Estudo conduzido por Sturion ${ }^{[6]}$ revelou, no tocante às refeições distribuídas pelo PNAE, que os adolescentes preferiam as preparações salgadas e do tipo "lanche", enquanto entre os de menor idade as preparações doces eram mais bem aceitas.

Com relação à refeição distribuída no período do almoço, nota-se que enquanto 79\% dos alunos da unidade A (autogestão) aderiram ao programa, $90 \%$ dos escolares da unidade B (terceirizada) realizaram as refeições distribuídas pelo PNAE. Embora estas percentagens de adesão sejam consideradas elevadas, de acordo com critério adotado por Sturion ${ }^{[6]}$, é importante destacar que, com a jornada integral (maior período em que o aluno permanece na unidade de ensino), a adesão de $79 \%$ dos escolares da unidade A a uma refeição importante, como a realizada no horário do almoço, não pode ser considerada satisfatória. A não adesão ao PNAE significa que a criança/adolescente, provavelmente, permanecerá expressivo período de tempo sem se alimentar adequadamente, condição que invariavelmente causará prejuízos, tais como alterações nos níveis de glicemia, redução na capacidade de aprendizagem e concentração, entre outros ${ }^{[25]}$.

Analisando-se as diferenças observadas entre as escolas, alguns fatores relacionados às características dos alunos, tais como os distintos grupamentos etários dos estudantes matriculados nas escolas e o nível socioeconômico (a unidade A localizava-se na região central da cidade, enquanto a unidade $\mathrm{B}$ estava localizada em bairro periférico) podem refletir sobre a aceitabilidade das refeições e a adesão ao Programa ${ }^{[26,27]}$. Além da idade e do nível socioeconômico dos escolares, outros aspectos, como o cardápio oferecido nas escolas, a presença de cantinas, e o atendimento dispensado pelas merendeiras no momento da distribuição das refeições podem influenciar a aceitação e a adesão dos escolares ao PNAE ${ }^{[28]}$.

Adicionalmente às elevadas proporções de adesão e de aceitabilidade dos escolares da unidade $\mathrm{B}$ (terceirizada) às refeições distribuídas no período do almoço, o reduzido porcionamento das preparações representa aspecto que pode ter contribuído para o expressivo percentual de repetições nesta unidade (Tabela 4).

Cabe destacar que a empresa prestadora de serviços de alimentação (unidade B) seguiu, para a elaboração das refeições, as especificações previstas para a "terceirização", descritas em requisição elaborada pelos gestores do PNAE do município. $\mathrm{Na}$ referida requisição, foram registrados, além dos cardápios e dos ingredientes que a empresa deveria utilizar, as quantidades per capita dos alimentos crus, não sendo identificados, no entanto, os rendimentos dos mesmos (porcionamento). Por meio da análise do volume médio das refeições servidas aos alunos na unidade B, pela empresa, foi possível verificar que as porções prontas equivaliam às descritas na requisição para os alimentos crus, não sendo observado, pela empresa, o rendimento das preparações (não especificado na requisição). 
Tal condição evidencia uma das principais dificuldades da opção pelo modelo de gestão de terceirização do Programa: a necessidade, por parte dos estados e municípios, de elaboração de editais e contratos nos quais os serviços sejam especificados de forma pormenorizada. De acordo com Nogueira ${ }^{[4]}$, a qualidade, o preço, os prazos e as obrigações da empresa devem estar bem detalhados no contrato, bem como as penalidades, caso as cláusulas não sejam cumpridas.

Stolarski ${ }^{[8]}$ registrou a dificuldade de parcela dos municípios que adotaram a terceirização, tais como Curitiba e São Luis, em informar corretamente o número de refeições a ser servido em cada unidade de ensino, bem como eventuais alterações nas programações da escola, acarretando, dessa forma, em desperdício de alimentos e em pagamento às empresas por refeições não consumidas.

É importante ressaltar que a empresa terceirizada recebeu da Prefeitura como pagamento pelo serviço um valor fixo, calculado pelos técnicos municipais com base no número de alunos matriculados na unidade de ensino e no período de atendimento do serviço, não havendo, portanto, pagamento adicional que envolvesse as repetições realizadas pelos alunos.

Uma das principais dificuldades enfrentadas na autogestão do PNAE referese à disponibilidade e à capacitação de pessoal para as atividades técnicas e administrativas $[6,8]$. No município de Piracicaba (SP), por exemplo, a Prefeitura contava, em 2006, com 250 merendeiras contratadas por meio de concurso, sendo que
175 estavam em atividade, 64 em disfunção (exercendo atividades que não estavam relacionadas ao preparo das refeições do PNAE) e 11 afastadas por licenças médicas. Tendo em vista as tarefas repetitivas exercidas pelas merendeiras; as estruturas físicas inadequadas das cozinhas; a elaboração de refeições que utilizam produtos in natura, que exigem etapas adicionais para o pré-preparo (como a desinfecção, descascamento, corte); e a média de idade das merendeiras (acima de 40 anos) eram constantes os pedidos de afastamentos das merendeiras por motivo de saúde, culminando em adaptações na função, com restrições, ou disfunção. Em 2003, visando-se à minimização dos problemas advindos da escassez de recursos humanos, a Prefeitura alterou a forma de contratação de pessoal e, em 2006, contava com a prestação de serviços de 195 merendeiras contratadas por meio de processo de terceirização ${ }^{[28]}$.

$\mathrm{Na}$ presente pesquisa, a unidade $\mathrm{A}$ contava com funcionárias contratadas pela Prefeitura por meio de empresa terceirizada. Eram responsáveis pelo preparo e distribuição das refeições na escola B as merendeiras da empresa terceirizada (na refeição do almoço), e uma funcionária da Prefeitura (para os lanches da manhã e da tarde). Analisando-se os dados da Tabela 5, verifica-se que o salário pago pela Prefeitura do município superava os valores adotados pelas empresas prestadoras do serviço. Nota-se que, no caso de Piracicaba (SP), onde expressiva parcela das unidades de ensino conta tanto com merendeiras contratadas pela Prefeitura quanto aquelas de empresa terceirizada, as diferenças salariais e na carga horária das atividades podem criar conflitos entre as funcionárias, dificultando a 
convivência e o cumprimento das atribuições, repercutindo negativamente na implementação do Programa.

Nogueira ${ }^{[4]}$ analisando a autogestão do PNAE na cidade de Campinas (SP) relatou que as funcionárias efetivas (cozinheiras e ajudantes de cozinha) frequentemente apresentavam doenças ocupacionais, causadas pelas más condições estruturais das cozinhas, equipamentos e utensílios. Segundo o referido autor, a solução encontrada para muitos municípios foi a contratação de mão-de-obra por meio da terceirização, porém a alta rotatividade e a baixa qualificação dos funcionários contribuíam frequentemente para o não atendimento das exigências envolvidas na manipulação dos alimentos.

Tendo por base os dados da Tabela 5, destaca-se o reduzido tempo de contratação, pela empresa terceirizada, das funcionárias para atuação na área de alimentação escolar. É importante considerar que as alterações envolvendo os funcionários nas escolas exigem constantes treinamentos por parte da empresa, visando-se à adequação da adoção dos procedimentos de higiene e preparo exigidos para a nova função. Por meio dos relatos das merendeiras, os treinamentos eram realizados pela empresa no momento da contratação e com periodicidade semestral ou anual. Por outro lado, a agilidade da empresa em substituir o funcionário, sempre que necessário, representa uma vantagem quando comparada à morosidade envolvida nos trâmites da administração pública ${ }^{[29]}$. As merendeiras da Prefeitura, por exemplo, quando são afastadas por motivo de saúde, aposentadoria, ou até mesmo falecimento, não podem ser substituídas sem a realização de concurso público.

Deve-se considerar, também, que com a ampliação da jornada de aulas e com a introdução no cardápio de refeições mais complexas, incluindo hortaliças, por exemplo, que necessitam frequentemente de etapas adicionais de pré-preparo, o aumento das atividades realizadas pelas merendeiras pode acarretar na necessidade de novas contratações pelo município. Segundo Teixeira et al. ${ }^{[30]}$, não existem parâmetros que definam o número de merendeiras necessárias para desempenhar suas funções, sendo que este dependerá da complexidade dos cardápios, existência de produtos formulados ou in natura nas preparações, alimentos pré-processados, condições físicas das cozinhas, equipamentos industriais, sistema de distribuição, horário de refeição e jornada de trabalho das merendeiras.

Sturion ${ }^{[6]}$ registra que uma das formas para melhoria da eficiência do programa de alimentação é a manutenção de um quadro técnico e operacional com quantidade suficiente de membros, periodicamente treinados, a fim de cumprir os objetivos do programa e as normas estabelecidas, com atuação integrada com os órgãos de vigilância municipal e/ou federal.

Aspecto positivo identificado na presente pesquisa refere-se ao treinamento recebido pelas merendeiras, tanto no modelo de autogestão quanto no terceirizado. A realização de treinamentos periódicos, visando à correta adoção das boas práticas no ambiente de trabalho, traz como vantagens a aquisição, pelas merendeiras, de conhecimentos para o adequado desempenho das funções no 
ambiente escolar e a redução da resistência em segui-los ${ }^{[31]}$.

Um dos principais problemas enfrentados pelos gestores estaduais e municipais do PNAE, além daqueles decorrentes do número insuficiente de merendeiras, refere-se à escassez de recursos para a manutenção das condições de infraestrutura das cozinhas que sediam $o$ Programa e para a aquisição de equipamentos [8]. É de responsabilidade dos estados e municípios a manutenção da estrutura física e a contratação de recursos humanos nas unidades pertencentes às suas respectivas redes de ensino ${ }^{[1]}$. Vale registrar que o governo do estado de São Paulo destinou recursos adicionais às unidades integrantes do projeto "Escola de tempo integral", com vistas à realização de reformas da estrutura das unidades de ensino que sediavam o projeto. Tais recursos possibilitaram a reforma da cozinha na escola $\mathrm{B}$, que teve, neste período, as refeições do PNAE terceirizadas. À época da pesquisa, a escola A não havia passado por reformas.

De forma similar ao identificado na presente pesquisa, Sturion ${ }^{[6]}$, avaliando as condições estruturais do PNAE em dez municípios brasileiros, verificou que prevaleceu nas escolas $(n=20)$ a falta de requisitos necessários para a conservação dos alimentos (tais como telas nas janelas, e prateleiras e estrados adequados); além de ausência de área específica para o armazenamento do lixo e de sanitários exclusivos para o uso do pessoal envolvido com o Programa.
Stolarski ${ }^{[8]}$ registrou que independentemente da região e da modalidade de gestão do PNAE, as precárias condições estruturais, principalmente quanto às dimensões dos ambientes, conservação e disponibilidade de equipamentos para refrigeração constituem-se em entraves para a operacionalização eficaz do Programa.

No que se refere às condições de higiene dos serviços (Tabela 6), cabe registrar a utilização, pela empresa terceirizada, de produtos (sabonete antisséptico, toalhas de papel) para a correta higienização das mãos dos manipuladores de alimentos, além de produtos (à base de hipoclorito) para desinfecção de utensílios e hortaliças. $\mathrm{Na}$ escola A, observou-se que os produtos utilizados para higienização das mãos eram os mesmos adotados para a limpeza dos utensílios (detergente), não havendo produtos específicos para a desinfecção de alimentos como as hortaliças e as frutas.

Resultados semelhantes, no tocante à ausência de produtos adequados para a higienização das mãos dos manipuladores, desinfecção de alimentos e equipamentos, foram identificados para o PNAE em outros estudos ${ }^{[32,33,34]}$.

Aspectos positivos observados foram a utilização pelos manipuladores, em ambas as escolas, de uniformes completos (de cor branca, sapatos fechados, cabelos protegidos por touca); o bom asseio pessoal; e a adoção de práticas higiênicas adequadas (tais como não falar, tossir ou espirrar sobre os alimentos). Nas duas unidades de ensino os manipuladores lavavam frequentemente as mãos, porém na escola $\mathrm{A}$, a ausência de 
produtos adequados para esta finalidade pode ter reduzido a eficiência da desinfecção.

Oliveira et al. ${ }^{[32]}$, avaliando as condições higiênico-sanitárias de creches públicas e filantrópicas do município de São Paulo, verificaram que os manipuladores de alimentos contribuíam em maior proporção para o risco de contaminação das refeições distribuídas, em comparação ao risco atribuído às condições inadequadas de estrutura física das cozinhas. Segundo os referidos autores, os investimentos na capacitação de recursos humanos, por meio de treinamento e supervisão, envolvem menores custos e são mais fáceis de serem realizados do que reformas e melhorias da estrutura física, uma vez que estas últimas dependem, com maior intensidade, de investimentos financeiros e da decisão política/administrativa dos gestores do Programa.

$\mathrm{Na}$ presente pesquisa, as merendeiras afirmaram receber treinamentos com freqüência semestral ou anual (Tabela 5), situação que pode ter contribuído para a adoção de práticas de higiene adequadas na manipulação de alimentos, durante o período de realização do estudo. Cursos envolvendo o treinamento em higiene e em Boas Práticas devem ser ministrados aos manipuladores de alimentos constantemente, tendo em vista a importância que estes apresentam no controle da qualidade das refeições distribuídas pelo PNAE $^{[32,35,36,37]}$.

Outro aspecto relevante para a obtenção de refeições adequadas do ponto de vista microbiológico é o controle do binômio tempo-temperatura durante as fases de preparo e distribuição. Como pontos favoráveis, destacam-se que ambas as unidades contavam com equipamentos (geladeiras e freezers) para manutenção das matérias primas e ingredientes sob refrigeração ou congelamento. Além disso, nas duas unidades os alimentos atingiam temperatura adequada $\left(\geq 70^{\circ} \mathrm{C}\right)$ durante a cocção e permaneciam aquecidos (temperatura $\geq 65^{\circ} \mathrm{C}$ ) até o momento da distribuição. No sistema terceirizado, a refeição era transportada da unidade na qual era preparada até a escola B. As refeições foram transportadas em caixas térmicas (tipo hot box) mantidas a uma temperatura superior a $80^{\circ} \mathrm{C}$, em um veículo utilizado apenas para o transporte de alimentos.

Como pontos negativos, em ambas as escolas não era realizada medição da temperatura no recebimento dos gêneros perecíveis e durante a distribuição das refeições prontas aos escolares. Nota-se que na unidade $A$ as preparações prontas não permaneceram em temperatura adequada (superior a $60^{\circ} \mathrm{C}$ ) até o final da distribuição.

Rosa et al. ${ }^{[38]}$ monitoraram o tempo e a temperatura durante a distribuição de refeições do PNAE em 27 escolas municipais de Natal ( $R N)$, e verificaram que a totalidade das escolas apresentou concordância com a legislação no tocante à temperatura de cocção (superior a $70^{\circ} \mathrm{C}$ ). No entanto, em cerca de $90 \%$ das escolas as temperaturas ao final da distribuição apresentavam-se inadequadas (inferiores a $60^{\circ} \mathrm{C}$ ). Contribuiu para esses resultados o fato das preparações prontas permanecerem, durante a distribuição,expostas à temperatura ambiente, em recipientes que não mantinham a temperatura alcançada durante a cocção. 
$\mathrm{Na}$ presente pesquisa, na unidade $\mathrm{B}$ (terceirizada), a manutenção dos alimentos em caixas térmicas (hot box) durante a distribuição pode ter auxiliado na permanência das refeições em temperatura adequada até o término do período de intervalo. $\mathrm{Na}$ escola $\mathrm{A}$ (autogestão) os alimentos prontos permaneciam, à temperatura ambiente, em recipientes inadequados ao controle de temperatura. Segundo Rosa et al. ${ }^{[38]}$, a presença de responsáveis técnicos qualificados para a supervisão das atividades desenvolvidas nas cozinhas das escolas, bem como a aquisição de equipamentos que mantenham os alimentos preparados protegidos de contaminação e em temperatura correta constituem em medidas que podem contribuir para a obtenção de refeições seguras.

Vale registrar que apenas na unidade sob responsabilidade da empresa terceirizada houve a coleta de amostras das preparações para análise laboratorial e estavam disponíveis os manuais de Boas Práticas e os Procedimentos Operacionais Padronizados POPs. Tais medidas são importantes no controle de qualidade das refeições distribuídas pelo Programa.

Pelos resultados apresentados, é possível verificar a maior agilidade da empresa na tomada de decisões, no que se refere à possibilidade de reformas nas cozinhas que sediam o Programa, aquisição de equipamentos e adequação quanto às normas de higiene vigentes. Nota-se que a estrutura apresentada pela empresa é de difícil implementação pela Prefeitura devido aos escassos recursos destinados ao PNAE e à morosidade dos trâmites públicos.
É preciso considerar, no entanto, que a terceirização ocorreu por período experimental em uma única unidade de ensino do município. Tal situação pode ter favorecido o acompanhamento rigoroso do preparo e da distribuição das refeições. Era oportuna para a empresa a prestação de um serviço de qualidade, tendo em vista o interesse da administração pública pela terceirização da totalidade da rede de ensino do município. Não foi possível pelo presente estudo, no entanto, inferir que a empresa teria condições de oferecer o mesmo tipo de serviço para todas as escolas pertencentes ao município. Stolarski ${ }^{[8]}$ identificou nas capitais, Curitiba e São Luis, que contam com o sistema terceirizado, o reduzido número de empresas especializadas no atendimento terceirizado da alimentação escolar que apresentam estrutura compatível à demanda.

Outra limitação da contratação do serviço terceirizado envolve os custos desta modalidade de gestão, frequentemente incompatíveis com os repasses do governo federal $^{[8]}$.

Na Tabela 7 são registrados os valores referentes ao custo mensal do PNAE no município de Piracicaba, que envolve o atendimento a 52 escolas estaduais com jornada tradicional de ensino, com um fornecimento mensal médio de 418.765 refeições, a um custo unitário de $\mathrm{R} \$ 0,67$, para a refeição do intervalo, na qual é servida uma refeição mais completa, com alimentos salgados sólidos, característica do horário do almoço. Para as escolas que integraram o projeto "Escola de Tempo Integral", o custo da refeição do almoço foi mais elevado ( $\mathrm{R}$ \$ 1,37 para a escola em autogestão e $\mathrm{R} \$ 1,11$ na 
terceirizada), o que pode ser justificado pela maior contribuição nutricional exigida para as refeições distribuídas no período integral: à época da pesquisa, o governo de São Paulo estipulou que as refeições do Programa deveriam fornecer $50 \%$ das necessidades nutricionais dos escolares, enquanto as refeições do PNAE na jornada tradicional deveriam contribuir com $15 \%$ das necessidades dos alunos.

No que se refere aos valores repassados pelo FNDE para a execução do PNAE, estes equivalem, desde 2006, a R\$ 0,22 per capita para alunos matriculados na educação básica, e devem ser empregados exclusivamente para a aquisição de gêneros alimentícios. Os estados e municípios podem complementar os recursos recebidos pelo governo federal para a compra de alimentos. No caso de São Paulo, há uma complementação dos valores repassados aos municípios no montante de R\$ 0,12 para alunos matriculados nas escolas de ensino fundamental com jornada tradicional, e de $\mathrm{R} \$$ 0,24 per capita para unidades com período integral. Tendo por base os custos das refeições (Tabela 7), nota-se, portanto, que o governo municipal vem assumindo majoritariamente os custos envolvidos na manutenção do PNAE.

Furtuoso et al. ${ }^{[39]}$ também verificaram a maior participação municipal nos dispêndios mensais com o PNAE. Avaliando informações obtidas em 1997 (tendo como base o repasse do governo federal, na época, de R\$ 0,13) para 1.378 municípios brasileiros, os referidos autores registraram que em todas as regiões do país o programa era financiado, basicamente, pelos governos municipal (54\% dos recursos) e federal (38\%), sendo que os estados contribuíam com cerca de $8 \%$ dos dispêndios.

O custo unitário da refeição distribuída no período do almoço alcançou $\mathrm{R} \$$ 1,11 para a empresa terceirizada e $\mathrm{R} \$ 1,37 \mathrm{sob}$ administração da Prefeitura (Tabela 7). Analisando-se os custos da autogestão, nota-se que o item mão de obra (salários, encargos e benefícios das merendeiras e do pessoal da área administrativa) foi o que apresentou a maior contribuição (52\%) para o custo total do Programa, tanto nas escolas com jornada tradicional como naquelas com período integral. Gêneros alimentícios e gás corresponderam a cerca de $44 \%$ do custo do Programa. Avegliano e Cyrillo ${ }^{[40]}$ avaliaram os custos das refeições em unidades de alimentação e nutrição institucionais e também verificaram que a mão de obra representava a proporção mais importante dos custos de produção, com valor superior a $60,0 \%$, seguida pelos gêneros alimentícios, com $28,8 \%$.

Embora os custos com os serviços de terceirização ( $\mathrm{R} \$ 1,11)$, na presente pesquisa, sejam inferiores quando comparados aos obtidos pela administração da Prefeitura (R\$ $1,37)$, não se pode negligenciar o interesse das empresas em apresentar um serviço de qualidade por um custo reduzido, com vistas à consolidação de uma experiência exitosa, que obviamente seria levada em consideração no processo de decisão da administração pública, no caso de optar pela gestão terceirizada (para o atendimento dos alunos da totalidade da rede de ensino) do PNAE. Destaca-se que o custo do Programa administrado pela Prefeitura apresentou-se condizente com os valores praticados pelas empresas especializadas neste tipo de serviço. 
Entre as limitações do presente estudo, registra-se o reduzido período da adoção da terceirização no município, que ocorreu em caráter experimental. É preciso considerar, por exemplo, a necessidade de adaptação da empresa à realidade do PNAE municipal. Não deve ser desconsiderado também o período de acompanhamento (cinco dias) da rotina de operacionalização do PNAE. Recomenda-se, para estudos futuros, sobre modelos de gestão, a inclusão de maior número de dias de observação.

\section{Conclusões}

A presente pesquisa visou analisar a experiência da adoção da terceirização por município que tradicionalmente operacionalizava o PNAE no modelo de autogestão. Embora a implementação da terceirização tenha ocorrido em uma única escola da rede de ensino por período experimental, tendo curta duração, a análise deste modelo de gestão em Piracicaba (SP) permitiu avaliar algumas vantagens e desvantagens da sua adoção.

Entre os aspectos positivos merece destaque a disponibilidade de recursos e a maior agilidade das empresas para a manutenção da infraestrutura, cumprimento das normas de higiene e para a aquisição de equipamentos. No entanto, atenção especial deve ser dedicada pelos gestores públicos no que se refere à elaboração de documentos/editais onde constem as especificações dos serviços que devem ser realizados pelas empresas.

Tendo em vista a escassez de estudos relacionados à avaliação dos modelos de gestão do PNAE, enfatiza-se a importância da realização de novas pesquisas na área, acompanhando por maior período de tempo a operacionalização do Programa por gestores públicos e privados.

Cabe destacar que o acesso à alimentação escolar gratuita constitui-se em direito da criança e do adolescente, assegurado pela Constituição, e está incluído entre os eixos prioritários para a garantia da segurança alimentar e nutricional. Considerando-se o montante de recursos destinados ao PNAE, e as especificidades de estados e municípios para a operacionalização do Programa, ressalta-se a necessidade de avaliações sistemáticas, com vistas à ampliação da eficácia do mesmo.

\section{Referências Bibliográficas}

[1] Brasil. Ministério da Educação. Fundo Nacional de Desenvolvimento da Educação. Resolução CD/FNDE № 38 , de 16 de julho de 2009. Dispõe sobre o atendimento da alimentação escolar aos alunos da educação básica no Programa Nacional de Alimentação Escolar - PNAE. [citado em 2009 set 11]. Disponível em: http:/www.fnde.gov.br/home/ index.jsp?arquivo=/alimentacao_escolar.html

[2] Fundo Nacional de Desenvolvimento da Educação - FNDE. Alimentação escolar. 2009. [citado em 2009 set 11]. Disponível em:

http://www.fnde.gov.br/home/index.jsp?arq uivo=/ alimentacao_escolar.html

[3] Belaciano MI, Moura D de O, Silva ACP da. Merenda Escolar. Direito e garantia à merenda escolar. 1995. [citado em 2004 jun. 07]. Disponível em: http://www.inep.gov.br

[4] Nogueira RM. O Programa Nacional de Alimentação Escolar como uma política pública: o caso de Campinas - SP [dissertação]. Campinas: Universidade Estadual de Campinas; 2004. 155 p. 
[5] Stefanini MLR. Merenda escolar: história, evolução e contribuição no atendimento das necessidades nutricionais da criança [tese]. São Paulo: Universidade de São Paulo; 1997. 105 p.

[6] Sturion GL. Programa de alimentação escolar: avaliação do desempenho em dez municípios brasileiros [tese]. Campinas: Universidade Estadual de Campinas; 2002. $269 \mathrm{p}$.

[7] Vieira MNCM, Ferriani MGC, Gomes R, Santos GVB dos, Marchi EMM. Gestão de um programa de alimentação escolar em um município paulista. Segurança Alimentar e Nutricional. 2008; 15(1): 29-48.

[8] Stolarski MC. Caminhos da alimentação escolar no Brasil: análise de uma política pública no período de 2003-2004 [dissertação]. Curitiba: Universidade Federal do Paraná; 2005. 160 p.

[9] Weis B, Chaim NA, Belik W. Manual de gestão eficiente da merenda escolar. 2.ed. São Paulo: Margraf; 2005. 82 p.

[10] Silva MV. Contrastes regionais nos custos, qualidade e operacionalização do Programa Nacional de Alimentação Escolar - PNAE e seu impacto sobre os padrões alimentares da população brasileira. Relatório CNPq (Processo 504369/2003-2). Brasília: CNPq; 2006. 559 p.

[11] Agência Nacional de Vigilância Sanitária. Resolução RDC № 216, de 15 de setembro de 2004. Dispõe sobre Regulamento Técnico de boas práticas para serviços de alimentação. [citado em 2009 set 13]. Disponível em: http://elegis.anvisa.gov.br/leisref/public/showAct.p hp?Id=12 546

[12] Agência Nacional de Vigilância Sanitária. Resolução RDC № 275 , de 21 de outubro de 2002. Dispõe sobre o Regulamento Técnico de procedimentos operacionais padronizados aplicados aos estabelecimentos produtores/industrializadores de alimentos e a lista de verificação das boas práticas de fabricação em estabelecimentos produtores/industrializadores de alimentos. [citado em 2009 set 13]. Disponível em: http://www.anvisa.gov.br/legis/resol /2002/275_02rdc.htm

[13] Secretaria de Estado da Saúde do Estado de São Paulo. Centro de Vigilância Sanitária. Portaria № 6, de 10 de março de 1999. Aprova o Regulamento Técnico, que estabelece os parâmetros e critérios para o controle higiênico-sanitário em estabelecimentos de alimentos. [citado em 2009 set 13]. Disponível em: http://elegis.bvs.br/leisref/public/showAct.php?id= 20920\&word

[14] Secretaria de Estado da Saúde do Estado de São Paulo. Centro de Vigilância Sanitária. Ficha de inspeção de estabelecimentos na área de alimentos. 1994. [citado em 2009 set 13]. Disponível em: http://www.cvs.saude.sp.gov.br/

[15] Associação Brasileira das Empresas de Refeições Coletivas - ABERC. Manual ABERC de Práticas de Elaboração e Serviço de Refeições para Coletividade. 8 ed. São Paulo: ABERC; 2003.

[16] Araújo MOD, Guerra TMM. Alimentos per capita. 2 ed. Natal: Ed. Universitária UFRN; 1995. $272 \mathrm{p}$.

[17] Ornellas LH. Técnica dietética: seleção e preparo de alimentos. 7 ed. São Paulo: Atheneu; 2001. 330 p.

[18] Moraes MAC. Avaliação dos efeitos da merenda escolar dos alunos da $1^{\mathrm{a}}$ série do $1^{\mathrm{o}}$ grau na cidade de Paulínia - SP [tese Livre Docência]. Campinas: Universidade Estadual de Campinas; 1982. 178 p.

[19] Brandão TM. Avaliação da aceitação e preferências de cardápios do Programa de Merenda Escolar em escolas municipais do ensino fundamental da cidade de Campinas 
[dissertação]. Campinas: Universidade Estadual de Campinas; 2000. 91 p.

[20] Brasil. Ministério da Educação. Fundo Nacional de Desenvolvimento da Educação. Resolução № 32 , de 10 de agosto de 2006. Estabelece as normas para a execução do Programa Nacional de Alimentação Escolar - PNAE. [citado em 2006 maio 04]. Disponível em: http://www.fnde.gov.br/home/index.jsp?arq uivo=/alimentacao_escolar/alimentacao_esc. html

[21] The Statistical Analysis System [programa de computador]. Versão 8.2. Cary: SAS Institute Inc.; 2000.

[22] Martins R de CB, Medeiros MAT de, Ragonha GM, Olbi JH, Segatti MEP, Osele MR. Aceitabilidade da alimentação escolar no ensino público fundamental. Saúde em Revista. 2004; 6(13): 71-78.

[23] Flavio EF. Alimentação escolar e avaliação nutricional dos alunos do ensino fundamental das escolas municipais de Lavras, MG [tese]. Lavras: Universidade Federal de Lavras; 2006. 293 p.

[24] Vianna RP de T, Tereso MJA. Análise do programa de merenda escolar em Campinas. Revista Cadernos de Debate. 1997; 5: 46-76.

[25] Neumann D. Diagnóstico nutricional, consumo alimentar e critérios utilizados por adolescentes na seleção dos alimentos consumidos [tese]. Campinas: Universidade Estadual de Campinas; 2007. 222 p.

[26] Sturion GL, Silva MV, Ometto AMH, Furtuoso MCO, Pipitone MAP. Fatores condicionantes da adesão dos alunos ao Programa de Alimentação Escolar no Brasil. Rev Nutr. 2005; 18(2): 167-81.

[27] Danelon MS, Fonseca MCP da, Silva MV. Preferências alimentares no ambiente escolar. Segurança Alimentar e Nutricional. 2008; 15(2): 66-84.
[28] Pecorari R de CF. Uma proposta de inovação no cardápio escolar baseada na avaliação do Programa de Alimentação Escolar, de Piracicaba - SP [dissertação]. Araraquara: Universidade Estadual Paulista "Júlio de Mesquita Filho"; 2006. 167 p.

[29] Alcantara CM. Processo de terceirização na Secretaria Municipal de Saúde de Almirante Tamandaré, Paraná, Brasil. Cad. Saúde Pública. 2000; 16(3): 871-2.

[30] Teixeira SMFG, Oliveira ZMC, Rego JC, Biscontini TMB. Administração aplicada às unidades de alimentação e nutrição. São Paulo: Atheneu; 1997. 219 p.

[31] Torres SAM, Miranda A da S, Silva VA, Toledo SC, Silva MA, Rocha JF. Treinamento de manipuladores de alimentos: merendeiras. Hig. Aliment. 2006; 20(143): 33-36.

[32] Oliveira M de N, Brasil ALD, Taddei JA de AC. Avaliação das condições higiênico-sanitárias das cozinhas de creches públicas e filantrópicas. Ciência \& Saúde Coletiva. 2008; 13(3): 1051-60.

[33] Silva C, Germano MIS, Germano PML. Condições higiênico-sanitárias dos locais de preparação da merenda escolar, da rede estadual de ensino em São Paulo, SP. Hig. aliment. 2003; 17(110): 49-55.

[34] Danelon MS, Silva MV. Análise das condições higiênico-sanitárias das áreas de preparo e consumo de alimentos disponíveis para alunos de escolas públicas e privadas. Hig. Aliment. 2007; 21(152): 25-30.

[35] Chesca AC, Moreira PA, Andrade SCBJ, Martinelli TM. Equipamentos e utensílios de unidades de alimentação e nutrição: um risco constante de contaminação das refeições. Hig. Aliment. 2003; 17(114/115): 20-23.

[36] Rêgo JC, Guerra NB, Pires EF. Influência do treinamento no controle higiênico-sanitário de unidades de 
alimentação e nutrição. R. Nutr. PUCCAMP. 1997; 10(1): 50-62.

[37] Góes JAW, Furtunato DMN, Veloso IS, Santos JM. Capacitação dos manipuladores de alimentos e a qualidade da alimentação servida. Hig. Aliment. 2001; 15(82): 20-22.

[38] Rosa MS, Negreiros SRF de, Seabra LMJ, Stamford TLM. Monitoramento de tempo e temperatura de distribuição de preparações à base de carne em escolas municipais de Natal (RN), Brasil. Rev. Nutr. 2008; 21(1): 21-28.
[39] Furtuoso MCO, Ometto AMH, Sturion GL, Silva MV, Pipitone MAP, Oetterer M. Programa Nacional de Alimentação Escolar: uma análise regional dos custos. In: Livro de resumos do VI Congresso Brasileiro de Saúde Coletiva, v. 6; 2000; Salvador, Bahia: ABRASCO; 2000. p. 48.

[40] Avegliano RP, Cyrillo DC. Influência do tamanho das plantas de produção nos custos de refeições das unidades de alimentação e nutrição da divisão de alimentação COSEAS/USP. Rev. Nutr. 2001; 14(supl.): 21-26. 